\title{
Half Way to Hypusine-Structural Basis for Substrate Recognition by Human Deoxyhypusine Synthase
}

\author{
Elżbieta Wątor ${ }^{(D,}$, Piotr Wilk (1) and Przemysław Grudnik *(D) \\ Malopolska Centre of Biotechnology, Jagiellonian University, ul. Gronostajowa 7a, 30-387 Krakow, Poland; \\ elzbieta.wator@doctoral.uj.edu.pl (E.W.); wilk.piotr@uj.edu.pl (P.W.) \\ * Correspondence: przemyslaw.grudnik@uj.edu.pl
}

Received: 30 January 2020; Accepted: 26 March 2020; Published: 30 March 2020

\begin{abstract}
Deoxyhypusine synthase (DHS) is a transferase enabling the formation of deoxyhypusine, which is the first, rate-limiting step of a unique post-translational modification: hypusination. DHS catalyses the transfer of a 4-aminobutyl moiety of polyamine spermidine to a specific lysine of eukaryotic translation factor 5A (eIF5A) precursor in a nicotinamide adenine dinucleotide (NAD)-dependent manner. This modification occurs exclusively on one protein, eIF5A, and it is essential for cell proliferation. Malfunctions of the hypusination pathway, including those caused by mutations within the DHS encoding gene, are associated with conditions such as cancer or neurodegeneration. Here, we present a series of high-resolution crystal structures of human DHS. Structures were determined as the apoprotein, as well as ligand-bound states at high-resolutions ranging from 1.41 to $1.69 \AA$ A. By solving DHS in complex with its natural substrate spermidine (SPD), we identified the mode of substrate recognition. We also observed that other polyamines, namely spermine (SPM) and putrescine, bind DHS in a similar manner as SPD. Moreover, we performed activity assays showing that SPM could to some extent serve as an alternative DHS substrate. In contrast to previous studies, we demonstrate that no conformational changes occur in the DHS structure upon spermidine-binding. By combining mutagenesis and a light-scattering approach, we show that a conserved "ball-and-chain" motif is indispensable to assembling a functional DHS tetramer. Our study substantially advances our knowledge of the substrate recognition mechanism by DHS and may aid the design of pharmacological compounds for potential applications in cancer therapy.
\end{abstract}

Keywords: hypusination; deoxyhypusine synthase; EIF5A; translation; hypusine; post-translational modification; polyamines; spermidine; spermine; putrescine

\section{Introduction}

Hypusination is the post-translational modification of lysine to the unusual amino acid

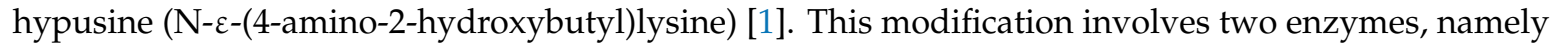
deoxyhypusine synthase (DHS) and deoxyhypusine hydroxylase (DOHH). In the first step of hypusination, the 4-aminobutyl moiety of spermidine (SPD) is transferred to the $\varepsilon$-amine group of lysine by DHS and forms deoxyhypusine, which is then hydroxylated by DOHH to hypusine. In humans, hypusine is present only in the eukaryotic translation factor 5A (eIF5A) [2,3]. Hypusination is the most specific post-translational modification known to date [4] and it is essential for eIF5A activity [5]. eIF5A is involved in elongation [6], termination [7] and the stimulation of peptide bond formation [8], and it facilitates protein synthesis by resolving polyproline-induced ribosomal stalling; thus, its role seems indispensable in proline repeat-rich protein synthesis [9]. The hypusination of eIF5A is essential for its activity in promoting cell proliferation [3,10-12]. Furthermore, there is evidence of eIF5A being important in different diseases such as diabetes, cancer and HIV infection [13-17]. 
In humans, there are two isoforms of eIF5A (eIF5A-1 and eIF5A-2) and both harbour hypusine modifications [18]. Despite the high conservation of the two isoforms, their functions may be significantly different [19]. The first isoform (eIF5A-1) is constitutively expressed in mammalian cells and overexpressed in human cancer tissues. In contrast to eIF5A, the expression of the other isoform (eIF5A-2) was detected only in specific tissues (testis and brain) or in various cancer types including colon, ovarian, bladder and liver [20]. Hypusinated eIF5A is essential for tumour growth, and its level of expression is closely related to the aggressiveness of cancers [21]. Moreover, the expression of the latter eIF5A-2 variant is a hallmark of many cancers [22,23].

DHS (EC: 2.5.1.46) is a cytosolic transferase involved in the first enzymatic step of the unique post-translational modification of eIF5A. In humans, DHS is encoded by the dhps gene, which is located on the 19th chromosome [24]. DHS is a 369 amino acid-long protein with a molecular mass of $41 \mathrm{kDa}$. In physiological conditions, DHS forms a homotetramer [25]. For its catalytic activity, the enzyme requires nicotinamide adenine dinucleotide (NAD) as a co-factor. DHS catalyses the transfer of 4-aminobutyl moiety of spermidine (SPD) to a specific lysine of eIF5A precursor, which results in deoxyhypusine formation. This reaction is the first, rate-limiting step of hypusination, and it plays a critical role in every eukaryotic living cell.

In detail, a DHS-catalysed reaction can be divided into four steps. During the first step, spermidine is oxidized in an NAD-dependent manner, which results in NADH and dehydrospermidine formation [26]. Generated dehydrospermidine is thereafter cleaved to yield diaminopropane (DAP), and the remaining butyloamine moiety is linked to the catalytic Lys329 via an imine bond [27]. This DHS-SPD intermediate is crucial for the entire reaction [28]. Upon eIF5A precursor recognition, the imine moiety is transferred to the $\varepsilon$-amino group of eIF5A Lys50. The last stage of the reaction catalysed by DHS is the reduction of the eIF5A Lys50 intermediate to deoxyhypusine through NAD regeneration [25].

Absent or diminished activity of DHS has a significant impact on cell proliferation $[29,30]$. At the beginning of 2019, mutations in the DHS-encoding gene were linked to a neurodevelopmental disorder, and a new hereditary recessive disease named 'DHPS deficiency' was described [31]. It has been also shown that the targeting of the first step of hypusination can suppress tumorigenesis [21]. The hypusination pathway can be inhibited by using a DHS inhibitor: N1-guanyl-1,7-diaminoheptane (GC7) [32,33], and this has shown promising results in the treatment of neuroblastoma [34] in combination with difluoromethylornithine (DFMO), which is a known inhibitor of ornithine decarboxylase [35]. However, GC7 is a spermidine-mimetic compound and thus, it may possibly also serve as an inhibitor of other SPD-binding proteins (e.g., spermine synthase), which is usually an undesired effect [13]. Therefore, the discovery of novel and more specific inhibitors is the current challenge of drug development.

Although the crystal structure of human DHS has been previously solved [36,37], its structure has been determined in either NAD- or GC7-bound states. Hence, we aimed to get molecular insights into the substrate-binding mechanism by solving DHS in the apo and polyamine substrate-bound states. Here, we report six high-resolution structures of wild-type (wt) human deoxyhypusine synthase, in the apo form and in complexes with polyamines, namely: spermidine, spermine (SPM) and putrescine (PUT). Our work presents the first structural insights into the substrate recognition and binding mechanism. Also, the structure of apo DHS reported herein is the first structure solved in the absence of the co-factor NAD. In addition, we demonstrate that a conserved, N-terminal "ball-and-chain" motif is essential for the assembly of the DHS homotetramer. Our research provides a solid basis for the development of specific DHS inhibitors, compounds which are likely to show significant anti-cancer activity. 


\section{Materials and Methods}

\subsection{Protein Expression and Purification}

Genes encoding full-length DHS (Uniprot: P49366, residues 1-369) and a truncated DHS $\Delta 1-52$ (residues 53-369) were optimized for an Escherichia coli expression system, synthesized (Genescript) and cloned with an N-terminal 6xHis-tag followed by a TEV cleavage site into a pET24d plasmid using NcoI/BamHI restriction sites. E. coli BL21(DE3) cells were transformed with the pET-24d vector containing the appropriate sequence. Terrific Broth medium supplemented with kanamycin $(50 \mu \mathrm{g} / \mathrm{L})$ was inoculated at 1:100 with an overnight LB culture started from a single colony. After reaching $\mathrm{OD}_{600}$ $=1-1.2$ the temperature was decreased from $37^{\circ} \mathrm{C}$ to $18^{\circ} \mathrm{C}$, and IPTG was added to a final concentration of $0.5 \mathrm{mM}$. Protein expression was carried out while shaking at $210 \mathrm{rpm}$ overnight. Cells were collected by centrifugation $\left(17,700 \times g, 12 \mathrm{~min}, 4^{\circ} \mathrm{C}\right)$ and re-suspended in lysis buffer $(50 \mathrm{mM}$ Tris- $\mathrm{HCl} \mathrm{pH} 7.8$, $300 \mathrm{mM} \mathrm{NaCl}, 20 \mathrm{mM}$ imidazole, 10\% glycerol, $10 \mathrm{mM} \beta-\mathrm{ME})$. Cells were disrupted in the presence of lysozyme (Sigma-Aldrich) by sonication (15 min, $5 \mathrm{~s}$ pulse/3 s pause cycles). Homogenous cell solution, with the addition of benzonase (Sigma-Aldrich), was subjected to centrifugation (53,000× $\mathrm{g}, 45 \mathrm{~min}$, $\left.4{ }^{\circ} \mathrm{C}\right)$. After centrifugation, the cleared lysate was applied onto an equilibrated affinity column $(5 \mathrm{~mL}$ HisTrap HP; GE Healthcare Europe GmbH, Freiburg, Germany) and washed with wash buffer (50 mM Tris- $\mathrm{HCl}$ pH 7.8, $200 \mathrm{mM} \mathrm{NaCl}, 40 \mathrm{mM}$ imidazole, 5\% glycerol, $5 \mathrm{mM} \beta-\mathrm{ME}$ ) to elute non-specifically bounded proteins. The protein of interest was eluted with the elution buffer $(50 \mathrm{mM}$ Tris- $\mathrm{HCl} \mathrm{pH} 7.8$, $200 \mathrm{mM} \mathrm{NaCl}, 400 \mathrm{mM}$ imidazole, 5\% glycerol, $5 \mathrm{mM} \beta-\mathrm{ME}$ ). Eluted protein was dialyzed against the storage buffer (50 mM Tris- $\mathrm{HCl}$ pH 7.8, $200 \mathrm{mM} \mathrm{NaCl}, 5 \mathrm{mM} \beta-\mathrm{ME}$ ) and subjected to overnight TEV protease cleavage during the second step of dialysis to remove the affinity tag. After HisTag cleavage, Tag-free protein was separated from the undigested protein and HisTagged-TEV protease during the reverse HisTrap column chromatography. Fractions containing HisTag-free protein were concentrated using Amicon Ultra (Millipore) concentrator (cut-off: 10,000 kDa) and subjected to size-exclusion chromatography (SEC) on a HiLoad 16/60 Superdex 75 column in a storage buffer. Peaks of highest purity were pooled, concentrated, aliquoted and flash-frozen in liquid nitrogen for further analysis.

\subsection{Protein Crystallisation}

The initial screening for crystallisation conditions was performed using a variety of available commercial screens at Structural Biology Core Facility (www.structuralbiology.pl). The first crystals of DHS were obtained from a Morpheus grid screen [38] by the sitting drop vapor diffusion technique at $293 \mathrm{~K}$ and later further optimized by the fine tuning of each component concentrations. The DHS wt protein was concentrated to $20 \mathrm{mg} / \mathrm{mL}$ and mixed in a 1:1 ratio with mother liquor solution consisting of a $0.025-0.125 \mathrm{mM}$ carboxylic acid mix, 30\%-60\% precipitant mix (MPD, PEG 1000, PEG 3350) and $100 \mathrm{mM}$ Tris-Bicine with a $\mathrm{pH}$ of 8.5. Obtained crystals were transferred to the cryo-protectant solution containing $25 \%$ of ethylene glycol in mother liquor supplemented with the ligands of interest (50 mM SPD, SPM, PUT, NAD, DAP or lysine (LYS)), soaked for 1-5 min and flash cooled in $\mathrm{LN}_{2}$.

\subsection{Diffraction Data Collection and Structure Determination}

Diffraction data were collected at the MX-beamline 14.1 at the BESSY II electron storage ring (HZB, Berlin, Germany) [39]. The diffraction data were processed using XDS as implemented in the XDSAPP package [40]. The DHS crystal structures were solved by molecular replacement with Phaser [41] using 1DHS as a search model. The obtained models were rebuilt using Coot [42] and refined using Phenix [43]. During the refinement, $\sim 1.5 \%$ of the reflections were used for cross-validation analysis to monitor the refinement strategy. Water molecules were automatically placed during structure refinement, or further added using Coot and subsequently manually inspected. The quality of the model was validated using MolProbity and PDB REDO [44] servers. All six structures have been determined to high resolution and refined to low values of $R_{\text {work }}$ and $R_{\text {free, which are indicators of }}$ good accuracy of the models. For all structures, satisfactory geometrical parameters were obtained. 
All significant data collection, structure refinements and validation statistics are summarized in Table 1. The analysis and comparison of structures were performed in PyMOL (Molecular Graphics System, Version 2.0 Schrödinger, LLC).

Table 1. Data collection and refinement statistics.

\begin{tabular}{|c|c|c|c|c|c|c|}
\hline DHS Structure & apo & NAD & NAD-SPD & SPD & SPM & PUT \\
\hline PDB ID & $6 \mathrm{XXH}$ & $6 \mathrm{XXI}$ & $6 \mathrm{XXJ}$ & $6 X X K$ & $6 X X L$ & $6 \mathrm{XXM}$ \\
\hline Wavelength $(\AA)$ & 0.9184 & 0.9184 & 0.9184 & 0.9184 & 0.9184 & 0.9184 \\
\hline Resolution range $(\AA)$ & $\begin{array}{c}46.22-1.52 \\
(1.57-1.52) *\end{array}$ & $\begin{array}{l}46.09-1.68 \\
(1.74-1.68)\end{array}$ & $\begin{array}{l}46.24-1.41 \\
(1.46-1.41)\end{array}$ & $\begin{array}{l}46.19-1.65 \\
(1.71-1.65)\end{array}$ & $\begin{array}{l}46.08-1.69 \\
(1.75-1.69)\end{array}$ & $\begin{array}{l}46.12-1.67 \\
(1.73-1.67)\end{array}$ \\
\hline Space group & $\mathrm{P} 3_{2} 21$ & $\mathrm{P}_{3} 21$ & $\mathrm{P} 3_{2} 21$ & $\mathrm{P} 3221$ & $\mathrm{P} 3221$ & $\mathrm{P}_{2} 21$ \\
\hline Unit cell $\left(\AA \AA^{\circ}\right)$ & $\begin{array}{c}104.97104 .97 \\
161.03 \\
90.090 .0 \\
120.0\end{array}$ & $\begin{array}{c}104.82104 .82 \\
160.50 \\
90.090 .0 \\
120.0\end{array}$ & $\begin{array}{c}105.49105 .49 \\
160.83 \\
90.090 .0 \\
120.0\end{array}$ & $\begin{array}{c}104.98104 .98 \\
160.90 \\
90.090 .0 \\
120.0\end{array}$ & $\begin{array}{c}104.90104 .90 \\
160.43 \\
90.090 .0 \\
120.0\end{array}$ & $\begin{array}{c}104.73104 .73 \\
160.67 \\
90.090 .0 \\
120.0\end{array}$ \\
\hline Total reflections & $\begin{array}{l}1592643 \\
(257143)\end{array}$ & $\begin{array}{c}979651 \\
(159039)\end{array}$ & $\begin{array}{l}1946524 \\
(308384)\end{array}$ & $\begin{array}{l}1371934 \\
(220304)\end{array}$ & $\begin{array}{l}2283917 \\
(365779)\end{array}$ & $\begin{array}{l}1191506 \\
(182975)\end{array}$ \\
\hline Unique reflections & $\begin{array}{l}157636 \\
(15594)\end{array}$ & $\begin{array}{l}116336 \\
(18588)\end{array}$ & $\begin{array}{l}198531 \\
(19596)\end{array}$ & $\begin{array}{l}123673 \\
(12190)\end{array}$ & $\begin{array}{l}114734 \\
(11265)\end{array}$ & $\begin{array}{l}118316 \\
(11679)\end{array}$ \\
\hline Multiplicity & 10.10 & 8.42 & 9.80 & 11.09 & 19.90 & 6.51 \\
\hline Completeness (\%) & $99.92(99.88)$ & 99.61 (98.77) & $99.82(99.48)$ & $99.80(99.05)$ & $99.71(98.40)$ & $99.81(99.45)$ \\
\hline Mean I/sigma(I) & $13.09(0.76)$ & $8.88(0.92)$ & $13.34(0.76)$ & $12.80(0.94)$ & $17.69(0.75)$ & $14.28(0.95)$ \\
\hline Wilson B-factor & 22.41 & 26.10 & 20.06 & 26.06 & 31.73 & 25.73 \\
\hline R-merge (\%) & $10.6(304.6)$ & $12.6(202.1)$ & $8.8(243.7)$ & $11.0(235.2)$ & $10.5(433.3)$ & $10.6(258.6)$ \\
\hline R-meas (\%) & $11.1(320.7)$ & $13.5(215.3)$ & $9.4(257.3)$ & $11.6(246.5)$ & $10.8(444.4)$ & $11.2(272.9)$ \\
\hline R-sym (\%) & $10.6(323.2)$ & $12.5(220.7)$ & $9.1(308.5)$ & $11.3(282.9)$ & $10.8(506.8)$ & $10.8(278.1)$ \\
\hline $\mathrm{CC}_{1 / 2}(\%)$ & $99.9(43.4)$ & $99.6(73.7)$ & $99.9(54.8)$ & $99.9(67.2)$ & $100.0(58.9)$ & $99.9(49.6)$ \\
\hline Reflections used in refinement & $\begin{array}{l}157555 \\
(15581)\end{array}$ & $\begin{array}{l}116220 \\
(11408)\end{array}$ & $\begin{array}{l}198411 \\
(19572)\end{array}$ & $\begin{array}{l}123538 \\
(12161)\end{array}$ & $\begin{array}{l}114606 \\
(11231)\end{array}$ & $\begin{array}{l}118271 \\
(11666)\end{array}$ \\
\hline Reflections used for R-free & $2099(208)$ & $2097(205)$ & $2096(207)$ & $2098(207)$ & $2099(206)$ & $2098(206)$ \\
\hline R-work (\%) & $15.42(34.35)$ & $15.39(34.91)$ & $14.25(34.82)$ & $15.53(36.48)$ & $16.17(39.78)$ & $16.05(33.51)$ \\
\hline R-free (\%) & $17.62(34.86)$ & $16.62(36.76)$ & $15.98(36.52)$ & $16.22(38.77)$ & $17.93(45.02)$ & $17.46(36.44)$ \\
\hline Number of non-hydrogen atoms & 6095 & 5916 & 6443 & 6013 & 6057 & 6186 \\
\hline macromolecules & 5320 & 5317 & 5635 & 5439 & 5477 & 5596 \\
\hline ligands & 22 & 243 & 215 & 169 & 107 & 20 \\
\hline solvent & 753 & 356 & 593 & 405 & 473 & 570 \\
\hline Protein residues & 667 & 679 & 692 & 691 & 675 & 692 \\
\hline RMS (bonds) & 0.010 & 0.021 & 0.011 & 0.018 & 0.013 & 0.010 \\
\hline RMS (angles) & 1.10 & 1.77 & 1.17 & 1.43 & 1.31 & 1.10 \\
\hline Ramachandran favored (\%) & 98.02 & 98.63 & 98.97 & 97.94 & 98.05 & 98.67 \\
\hline Ramachandran allowed (\%) & 1.98 & 1.37 & 1.03 & 2.06 & 1.95 & 1.33 \\
\hline Ramachandran outliers (\%) & 0.00 & 0.00 & 0.00 & 0.00 & 0.00 & 0.00 \\
\hline Rotamer outliers (\%) & 0.35 & 0.35 & 0.33 & 0.00 & 0.67 & 0.33 \\
\hline Clashscore & 3.00 & 3.43 & 5.47 & 5.28 & 6.78 & 3.02 \\
\hline Average B-factor & 34.78 & 39.05 & 29.52 & 36.93 & 47.86 & 38.77 \\
\hline macromolecules & 32.88 & 37.87 & 27.97 & 35.76 & 46.59 & 37.79 \\
\hline ligands & 51.62 & 54.97 & 44.86 & 55.55 & 69.85 & 55.71 \\
\hline solvent & 47.71 & 45.85 & 38.63 & 44.94 & 57.59 & 47.81 \\
\hline
\end{tabular}

* Statistics for the highest-resolution shell are shown in parentheses.

\subsection{Single Turnover Fluorescence Assay}

The single turnover fluorescence assay was performed as described previously [45]. Briefly, $5 \mu \mathrm{M}$ or $15 \mu \mathrm{M}$ of DHS was incubated in the presence of $1 \mathrm{mM}$ NAD (alone, or in the presence of $0.5 \mathrm{mM}$ GC7 or $1 \mathrm{mM}$ DAP) in $100 \mathrm{mM}$ Tris-Bicine $\mathrm{pH}=8.5$ buffer, and the fluorescence excited at $350 \mathrm{~nm}$ 
and emitted at $441 \mathrm{~nm}$ was recorded. After $\sim 2 \mathrm{~min}, \mathrm{SPD}, \mathrm{SPM}$, PUT or LYS was added to a final concentration of $1 \mathrm{mM}$ and measurement was immediately continued for $\sim 2 \mathrm{~min}$. An observed rapid burst of fluorescence, derived from a rising NADH concentration, was taken as the measure of DHS activity within the first step of its reaction. Each experiment was carried out at least three times.

\subsection{Analysis of Protein Stability}

To investigate the protein stability and determine the protein's melting temperature, the Thermal Shift Assay (TSA) was performed as described previously [46]. Briefly, the protein solution $(2 \mathrm{mg} / \mathrm{mL})$ was incubated with 1:500 diluted Sypro Orange dye and storage buffer. The fluorescence signal $\left(\lambda_{\mathrm{ex}}\right.$ $=492 \mathrm{~nm}, \lambda_{\mathrm{em}}=610 \mathrm{~nm}$ ) from Sypro Orange was determined as a function of temperature between 5 and $95^{\circ} \mathrm{C}$ in increments of $0.5^{\circ} \mathrm{C} / \mathrm{min}$. The melting temperature was calculated as the inflexion point of the fluorescence curve. At least three independent repeats were done.

\subsection{Analysis of the Protein Oligomeric State}

The oligomeric states of DHS and DHS $\Delta 1-52$ were investigated by size-exclusion chromatography coupled to multi-angle light scattering (MALS), together with measuring the refractive index (RI) using the Dawn Heleos 8+ and T-Rex detectors (Wyatt). Pure protein sample was separated on the XBridge BEH200 7.8 $\times 300$ (Waters) in $50 \mathrm{mM}$ Tris $\mathrm{H}=7.8,200 \mathrm{mM} \mathrm{NaCl}, 5 \mathrm{mM} \beta$-ME buffer at a flow rate of $1 \mathrm{~mL} \cdot \mathrm{min}^{-1}$. Results were analysed using the ASTRA6 software.

\subsection{FRET Measurements}

To investigate the DHS affinity to polyamine, a FRET experiment relying on the energy transfer from DHS W327 to the dihydronicotinamide ring of NADH was performed, as described previously [25]. Briefly, $5 \mu \mathrm{M}$ of DHS wt was incubated in the presence of $10 \mu \mathrm{M}$ NAD in $100 \mathrm{mM}$ Tris-Bicine $\mathrm{pH}=8.5$ buffer, and sequentially, $2 \mathrm{uL}$ of $50 \mu \mathrm{M}$ SPD or $1 \mathrm{mM}$ SPM were added to reaction mixture. After the addition of each substrate portion, the fluorescence signal $(\lambda e x=295 \mathrm{~nm}, \lambda \mathrm{em}=441 \mathrm{~nm})$ was recorded until saturation was achieved. Apparent $\mathrm{K}_{\mathrm{D}}$ values were calculated using the Hill model implemented in Graphpad Prism 8 (GraphPad Software, Inc., California, USA).

\section{Results}

\subsection{DHS Forms a Functional Tetramer}

The structure of apo DHS was determined by molecular replacement using the Protein Data Bank (PDB) entry 1DHS as a search model and refined to a resolution of $1.52 \AA$ with $R_{\text {work }} / R_{\text {free }}$ values of $15.42 \% / 17.62 \%$. In comparison, the previously reported structures have been refined at 2.2 and $3 \AA$ for NAD- and GC7-bound structures respectively, thus the resolution of the structure presented by us constitutes a major improvement and allows for a more detailed analysis [36,37].

DHS crystallised in the $\mathrm{P}_{2} 21$ space group with one tightly associated homodimer per asymmetric unit (ASU), with two active sites located at the dimer interface (Figure 1B). Each active site is formed by residues from both subunits. The DHS dimer is related by a two-fold axis with the identical dimer (Video S1), forming a dimer of dimers, which was previously identified as an active form of protein [47] and additionally confirmed by multiangle light scattering (MALS) measurements. In the refined structure, the electron density clearly defines the residues ranging from Ser28 to Met363. The loop containing residues 79-83 in chain A is poorly ordered compared to the rest of the protein, so these residues were not built due to insufficient definition by electron density. The core of DHS consists of five parallel beta-strands (S1, S2, S5, S6, S7) forming a Rossmann fold that is conserved in proteins that bind nucleotide co-factors (Figure S1B).

During the model building and structure refinement, we observed that Cys177, in both chains as well as in all of the herein presented structures, is covalently modified to a $\beta$-mercaptoethanol (BME) adduct. This may be irrelevant to structural studies, but it is noteworthy, particularly in light of the 
fact that in the absence of BME (or in the presence of another reductive agent as DTT), DHS does not crystallise, or it forms crystals characterised by poor morphology that are unsuitable for diffraction studies (Figure S1D).

A
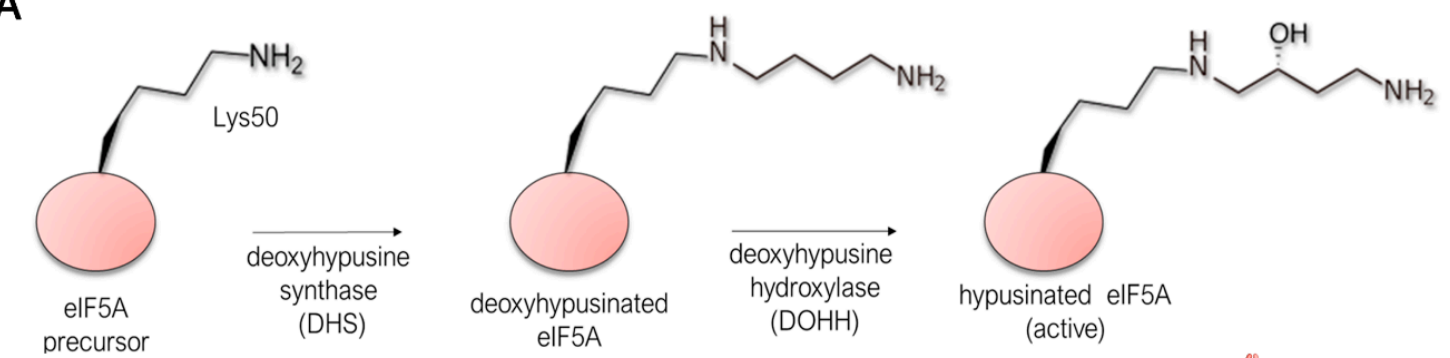

B

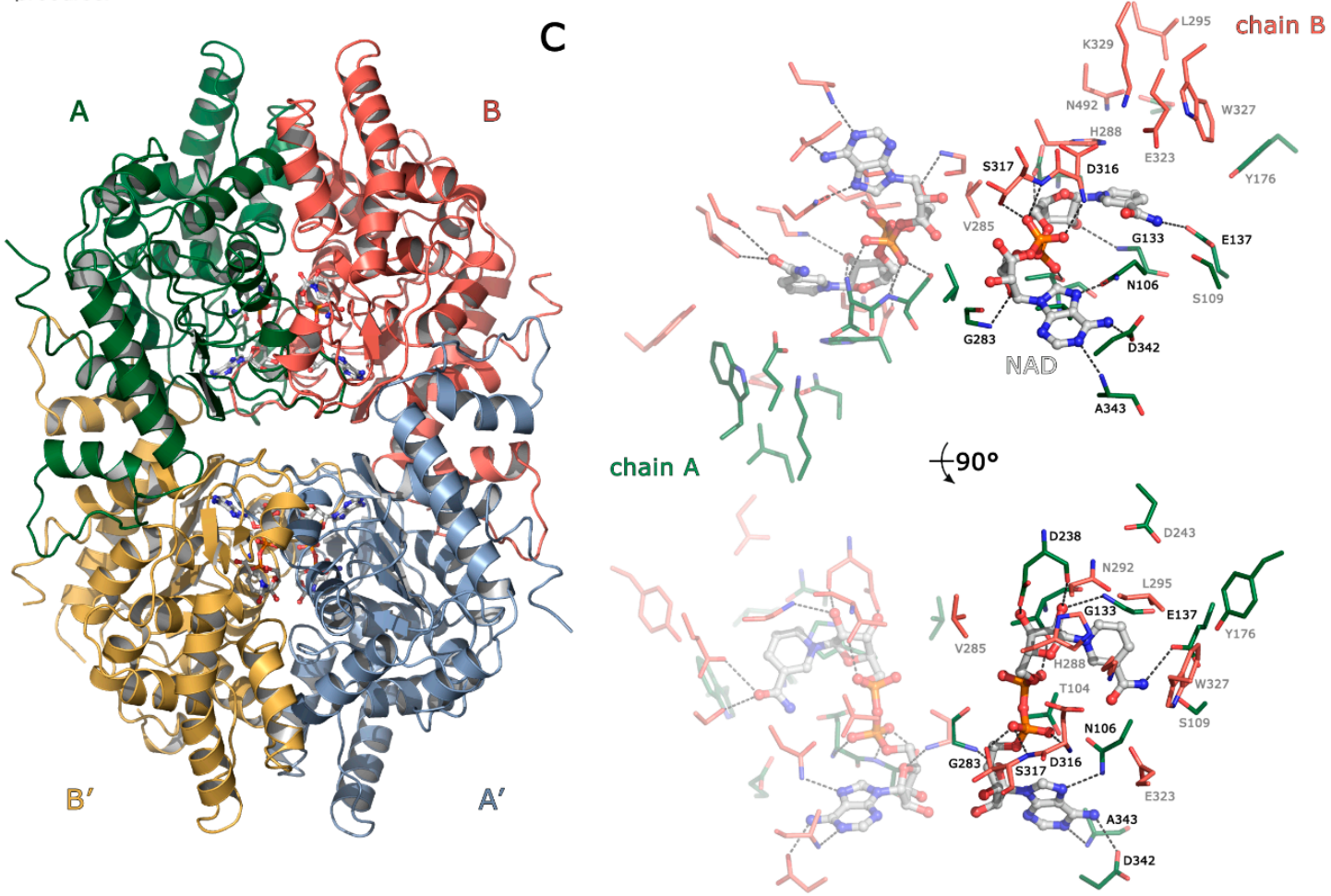

Figure 1. A deoxyhypusine synthase (DHS) overview. (A) A schematic representation of the hypusination pathway with DHS catalysing the first step, i.e., the transfer of the 4-aminobutyl moiety from spermidine (SPD) to a specific lysine side chain of eukaryotic initiation factor 5A (eIF5A) and deoxyhypusine hydroxylase $(\mathrm{DOHH})$ finalising the modification by deoxyhypusine oxidation. (B) The structural organisation of the DHS tetramer. The tetramer is formed by two dimers with one (A-B, coloured green and red) observed in the asymmetric unit (ASU) of the crystal and the second dimer $\left(\mathrm{A}^{\prime}-\mathrm{B}^{\prime}\right.$, coloured blue and yellow) observed by crystallographic symmetry. Ligands are shown as sticks, to highlight the locations of active sites. (C) A close-up view of the active sites formed at the dimer interface in the binary DHS-nicotinamide adenine dinucleotide (NAD) complex. Two NAD molecules are bound symmetrically and coordinated by residues from both subunits. The co-factor is shown as balls and sticks with carbon atoms coloured white, and residues from chains A and B are shown as sticks, with carbon atoms in green and red respectively. Residues binding the co-factor are black, and residues completing the active site are grey. For clarity, one of the active sites is semi-transparent.

Using PDBePISA [48] analysis, we calculated the total buried area of the apo DHS tetramer to equal $34,410 \AA^{2}$, with a corresponding $\Delta G_{\text {int }}$ of $-73.6 \mathrm{kcal} / \mathrm{mol}$. The $\Delta \mathrm{G}_{\text {int }}$ value indicates the solvation free energy gain upon the formation of the assembly. The possible dimeric assemblies formed by monomers $\mathrm{A}: \mathrm{B}$ or $\mathrm{A}: \mathrm{B}^{\prime}$ (where $\mathrm{B}^{\prime}$ is a symmetry-related chain) encompass a significantly smaller buried 
area and less favourable $\Delta G_{\text {int }}$ values of $9710 \AA^{2} /-18 \mathrm{kcal} / \mathrm{mol}$ and $10,320 \AA^{2} /-9.1 \mathrm{kcal} / \mathrm{mol}$ respectively. The same is true for all of the five complexes analysed in this work. This analysis suggests that the tetramer form is significantly more stable than any of the isolated dimers, and it is in agreement with the previous findings [49].

The DHS dimer present in the ASU has two major interfaces formed between chains A and B $(\mathrm{A}: \mathrm{B})$ and between chain $\mathrm{A}$ and a symmetry-related chain $\mathrm{B}\left(\mathrm{A}: \mathrm{B}^{\prime}\right)$ (Figure 1B). The A:B interface of $2822 \AA^{2}$ and $\Delta G_{i}$ of $-21.4 \mathrm{kcal} / \mathrm{mol}$ involves $17 \mathrm{H}$-bonds and 16 salt bridges. This interface forms a binding pocket for NAD and SPD. The A:B' interface of $2425 \AA^{2}$ and $\Delta G_{i}$ of $-33.9 \mathrm{kcal} / \mathrm{mol}$ is more hydrophobic in nature and encompasses only nine $\mathrm{H}$-bonds and nine salt bridges. The diagonal chain interactions $\mathrm{A}: \mathrm{A}^{\prime}$ and $\mathrm{B}: \mathrm{B}^{\prime}$ play only a marginal role in complex formation with the interface's area of approximately $400 \AA^{2}$ and a $\Delta \mathrm{G}_{\mathrm{i}}$ of $-4 \mathrm{kcal} / \mathrm{mol}$.

The structure of human DHS in complex with NAD was previously reported by Liao et al. at $2.2 \AA$, and the complex has been solved in the tetragonal space group with a single monomer in the ASU [37]. We have determined the structure of the DHS-NAD binary complex at $1.68 \AA$ with $R_{\text {work }} / R_{\text {free }}$ values of $15.39 \% / 16.62 \%$. A comparison of both structures shows only small differences, with an overall C $\alpha$ RMSD of $\sim 0.22 \AA$. Thus, we used the higher resolution structure for all further comparisons described herein. The electron density maps clearly show the presence of one NAD molecule bound in each of the active sites formed at the dimer interface (Figure $1 \mathrm{C}$ for details).

\subsection{Crystal Structures of Binary DHS-Spermidine and Ternary DHS-Spermidine-NAD Complexes}

To uncover the structural determinants of substrate recognition by DHS, we attempted to solve its crystal structure in the ligand-bound form. We have performed a number of crystal soaking experiments utilising a wide range of DHS substrates. First, we successfully soaked, measured the X-ray diffraction, solved and refined the structure of the DHS-SPD complex in the absence of the NAD co-factor. The structure was refined to a $R_{\text {work }} / R_{\text {free }}$ of $15.53 \% / 16.22 \%$ at a $1.65 \AA$ resolution. Subsequently, we solved and refined the structure of the DHS-NAD-SPD complex to a $1.41 \AA$ resolution with $\mathrm{R}_{\text {work }} / \mathrm{R}_{\text {free }}$ values of $14.25 \% / 15.98 \%$. Both protein models encompass residues 8-363 of chain $\mathrm{A}$ and 28-363/364 of chain B, which all could be unambiguously fitted into the calculated electron density. In contrast to apo and NAD-bound structures, an additional N-terminal fragment containing regions from Glu8 or Ala9 is observed in chain A of spermidine bound complexes. The asymmetric unit of the structure accommodates two SPD molecules bound symmetrically to the two neighbouring active sites jointly created by two DHS monomers. It appears that in both binary and ternary complexes, the polyamine molecule is bound in the congenial orientation. The details of ligand binding are depicted in Figure 2A. 
A

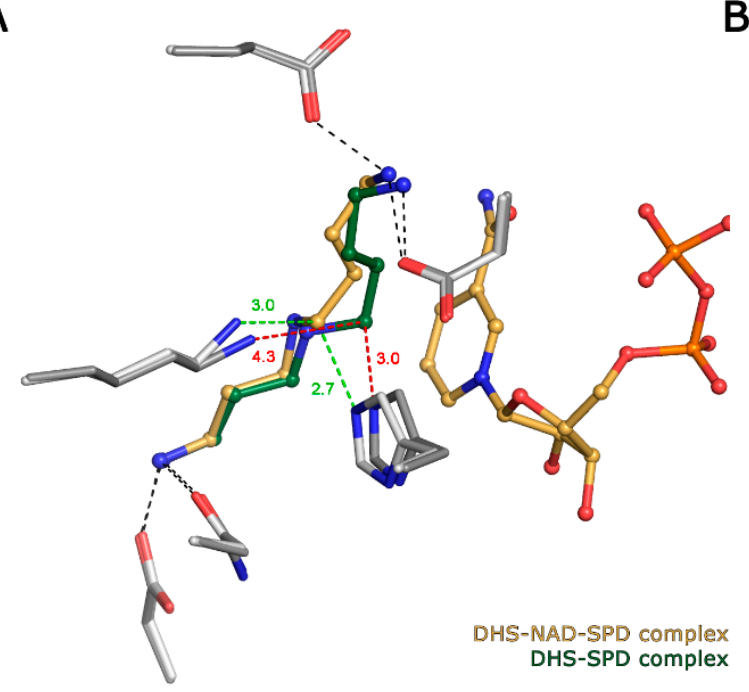

B

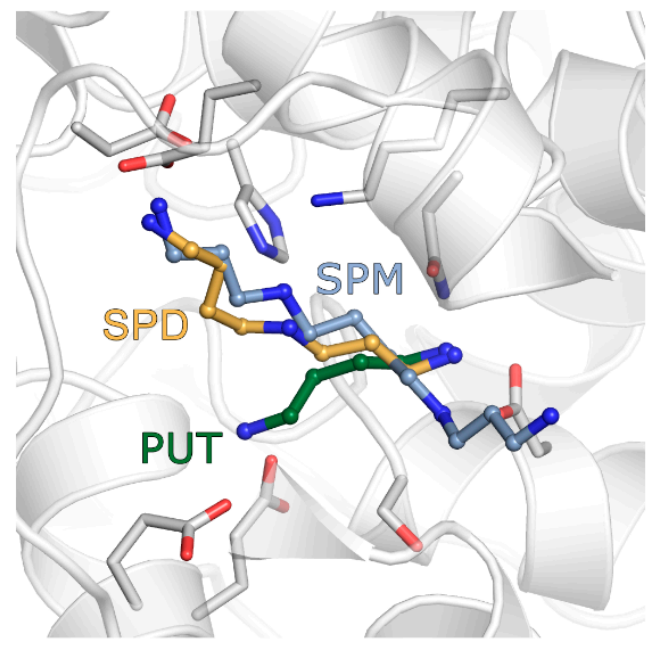

C

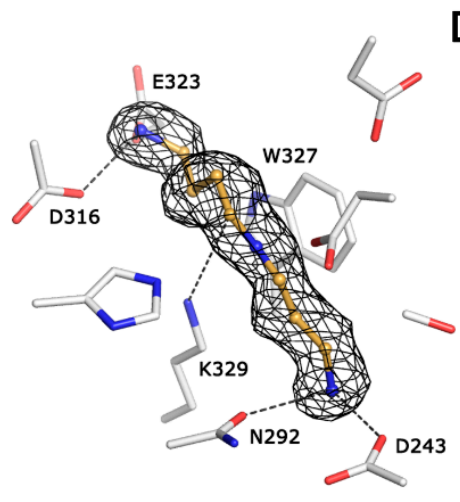

D

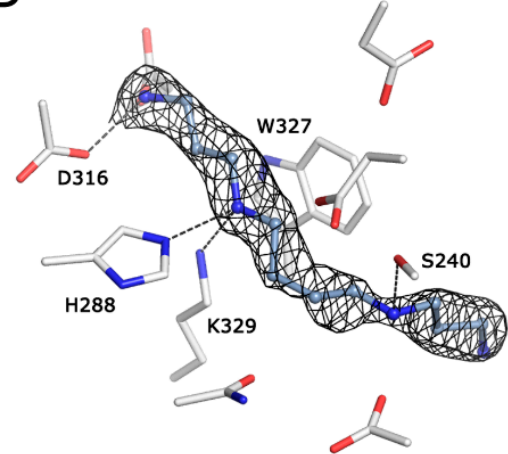

E

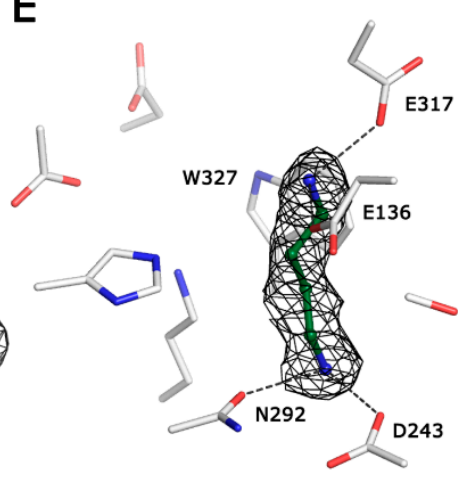

F

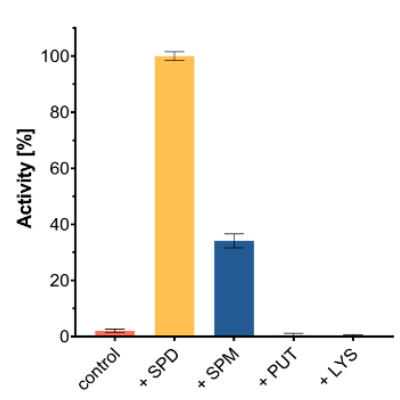

G

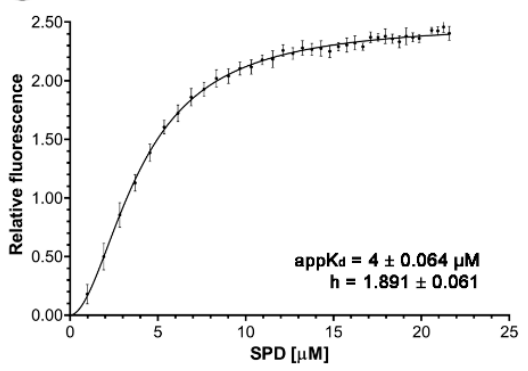

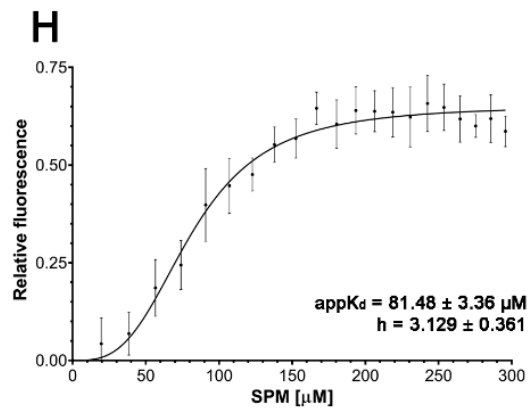

Figure 2. The binding of polyamines to DHS. (A) The superposition of binary DHS-SPD and ternary DHS-NAD-SPD complexes. The ligands are shown as balls and sticks, with carbons coloured green in binary complexes and yellow in ternary complexes respectively. The side chains for the residues coordinating SPD are shown as sticks, in light grey for DHS-NAD-SPD and in dark grey for DHS-SPD. The change in conformation of SPD induced by the presence of NAD is highlighted by a change of distances between $\mathrm{C} 5$ and His288 and the catalytical lysine 329, coloured red and green for binary and ternary complexes respectively. (B) Superposition of the DHS-SPD, DHS-SPM and DHS-PUT complex structures shows the relative positions of the investigated polyamines in the active site. Ligands are represented as balls and sticks, and the residues forming binding sites are shown as sticks. (C-E) The binding of SPD, SPM and PUT is shown with ligand as balls and sticks. 2Fo-Fc composite omit maps countered at $1 \sigma$ are shown as a black mesh for each ligand. Residues taking part in the binding of each ligand are labelled. (F) The relative activity of DHS, expressed as an increase in the NAD fluorescence in the presence of various ligands. (G,H) A FRET binding assay for SPD and SPM. 


\subsection{DHS Binds Spermine and Putrescine}

To verify if the DHS active site is able to accommodate other physiologically relevant polyamines, we crystallised it in complexes with SPM and PUT. In the cellular context, tetraamine SPM is synthesised by spermine synthase from SPD and previous studies have shown no or weakly detectable binding of SPM by DHS [47]. We have determined a crystal structure of DHS-SPM complex at a $1.69 \AA$ resolution. The final refined structure is characterised by $R_{\text {work }} / R_{\text {free }}$ values of $16.17 \% / 17.93 \%$ respectively and accommodates residues 26-363 of chain A and 28-364 of chain B. Likewise, in the DHS-SPD complex, the electron density for two SPM molecules symmetrically bound could be observed (Figure 2D). In conclusion, the SPM binding mode is highly similar to that described for SPD.

Another physiologically relevant polyamine is PUT, a diamine synthesised in the polyamine synthesis pathway [50]. Ornithine and agmatine are precursors of PUT that are produced in ornithine decarboxylase (ODC)- or agmatinase (AGMAT)-catalysed reactions respectively. The PUT synthesis engaging arginase and ODC has been named the "classical route" in contrast to a so-called "non-classical route" that involves arginine decarboxylase and AGMAT [51]. In principle, PUT serves as the main precursor for spermidine synthesis in the reaction catalysed by spermidine synthase [52]. To test whether PUT is able to bind DHS, we crystallised and solved the DHS-PUT complex structure. The structure has been refined to $16.05 \% / 17.46 \%$ at a $1.67 \AA$ resolution. In both subunits present in the ASU, an additional electron density map was present in the active site, which was interpreted as PUT (Figure 2E).

Next, we also attempted to co-crystalize DHS in complex with 1,3-diaminopropane (DAP), which is the by-product of deoxyhypusine formation. However, our efforts resulted in an apo crystal structure with no observable electron density for a putative ligand.

\subsection{Structural Comparison of Polyamine Binding by DHS}

Based on our crystallographic studies, we show that three polyamines, namely SPD, SPM and PUT, but not DAP — which is a product of the DHS-catalysed reaction-can bind in the enzyme's active site (Figure 2B). They all adopt an elongated conformation, yet display discrete differences which may discriminate between the substrate and its homologues. Notably, only minor differences in ADPs on the surface of the protein, and no significant structural changes, were observed between the compared binary structures outside the active site.

The physiological substrate, SPD, is anchored in the active site by its two terminal amine groups, with N1 forming a hydrogen bond with the side chain of D316, and N10 forming two H-bonds with the side chains of D243 and N292. The secondary amine (N6) is not involved in any hydrophilic interactions, but is stabilised by delocalised electrons from the nearby W327 $(\sim 2.7 \AA)$. The distance from the $\varepsilon$-amine group of the catalytic K329 to SPD's C5 is 4.23/4.22 $\AA$ in the binary complex, but is significantly shortened to $3.37 / 2.93 \AA$ in the ternary one in the presence of NAD. Moreover, in the ternary (but not in the binary) complex, the C5 of SPD comes into close $(2.75 / 2.65 \AA)$ contact with the $\mathrm{N} \varepsilon$ of the $\mathrm{H} 288$, which may play a role in stabilising a transition state during the nucleophilic attack of SPD C5 on K239 N $\varepsilon$. Notably this orientation places the leaving group (DAP) close to the surface and facilitates its escape from the active site (Figure 2C).

SPM is similarly anchored by its N1 to the side chain of D316 and additionally to E323, but its chain is slightly bent in comparison to SPD due to the interaction of the secondary amine (N5, corresponding to C5 in SPD) with both K329 and H288, and these interactions prevent the occurrence of a nucleophilic attack (Figure 2D). The N10 in SPM (corresponding to N10 in SPD) maintains the interaction with D243, but instead of forming an H-bond with N292, it is shifted towards S240, forming a new H-bond. This interaction directs the remaining, uncoordinated part of SPM (C11-N14), to the active site exit. Noteworthily, despite the similar location of SPD and SPM in the active sites, both SPM molecules display significantly higher B-factor values as compared to SPD (Figure S2B-D).

PUT is a diamine that is significantly shorter than the other two investigated polyamines. In the active site, it is anchored by two H-bonds formed between N2 (corresponding to N10 in SPD) and the 
sidechains of D243 and N292. As it is shorter, the other end of PUT cannot reach the second anchoring point of SPD, but is rather deflected towards E136 and E137, forming salt bridges with their carboxylic groups. Hence, it is placed too distant to be involved catalytically with K329 (Figure 2E).

Surprisingly, based on the $\Delta \mathrm{G}_{\mathrm{i}}$ calculations for both SPD and SPM, in the range of $5-5.6 \mathrm{kcal} / \mathrm{mol}$, and $1.9-2.2 \mathrm{kcal} / \mathrm{mol}$ for PUT, there is no clear energetic difference between the binding of either of the polyamines. The shortest tested polyamine, DAP, could not be observed in the crystal structures despite using very high concentrations during soaking or co-crystallisation, which is expected for the product of the reaction.

\subsection{Spermidine and Spermine Cooperatively Bind DHS Active Sites}

The first step of the reaction executed by DHS is the NAD-dependent oxidative cleavage of spermidine [26]. Thus, to further qualitatively assess the polyamine binding specificity, we used a well-established, single-turnover fluorescence assay. An observed rapid burst of fluorescence is a qualitative measure of NADH oxidation and reflects DHS activity. Surprisingly, not only the natural substrate SPD, but also one of related polyamines SPM, can serve as a reductive agent for NADH formation (Figure 2F). The fluorescence signal for SPM is significantly lower than that observed for SPD. At the same time, we observed no signal for the third human polyamine PUT or for LYS-the amino acid that undergoes modification catalysed by DHS. Using the same assay, we also tested if the product of further spermidine cleavage, DAP, is able to inhibit the reaction. Our results clearly show that the presence of DAP partially inhibits the reaction, but the inhibitory effect is significantly lower than that described for the only known DHS inhibitor: GC7 (Figure S2F).

To compare the binding of SPD and SPM by DHS, we experimentally measured their apparent binding affinities using the FRET method, relying on the energy transfer from W327 to the dihydronicotinamide ring of NADH. We have analysed our data using the Hill slope binding model that accounts for DHS having four equipollent binding sites for polyamines. The calculated apparent $\mathrm{K}_{\mathrm{D}}$ values for SPD and SPM were $4 \pm 0.064$ and $81.48 \pm 3.36 \mu \mathrm{M}$, respectively (Figure 3F,G). The calculated Hill coefficient values (h) are $1.891 \pm 0.061$ and $3.129 \pm 0.361$, indicating positive cooperativity between binding sites. 


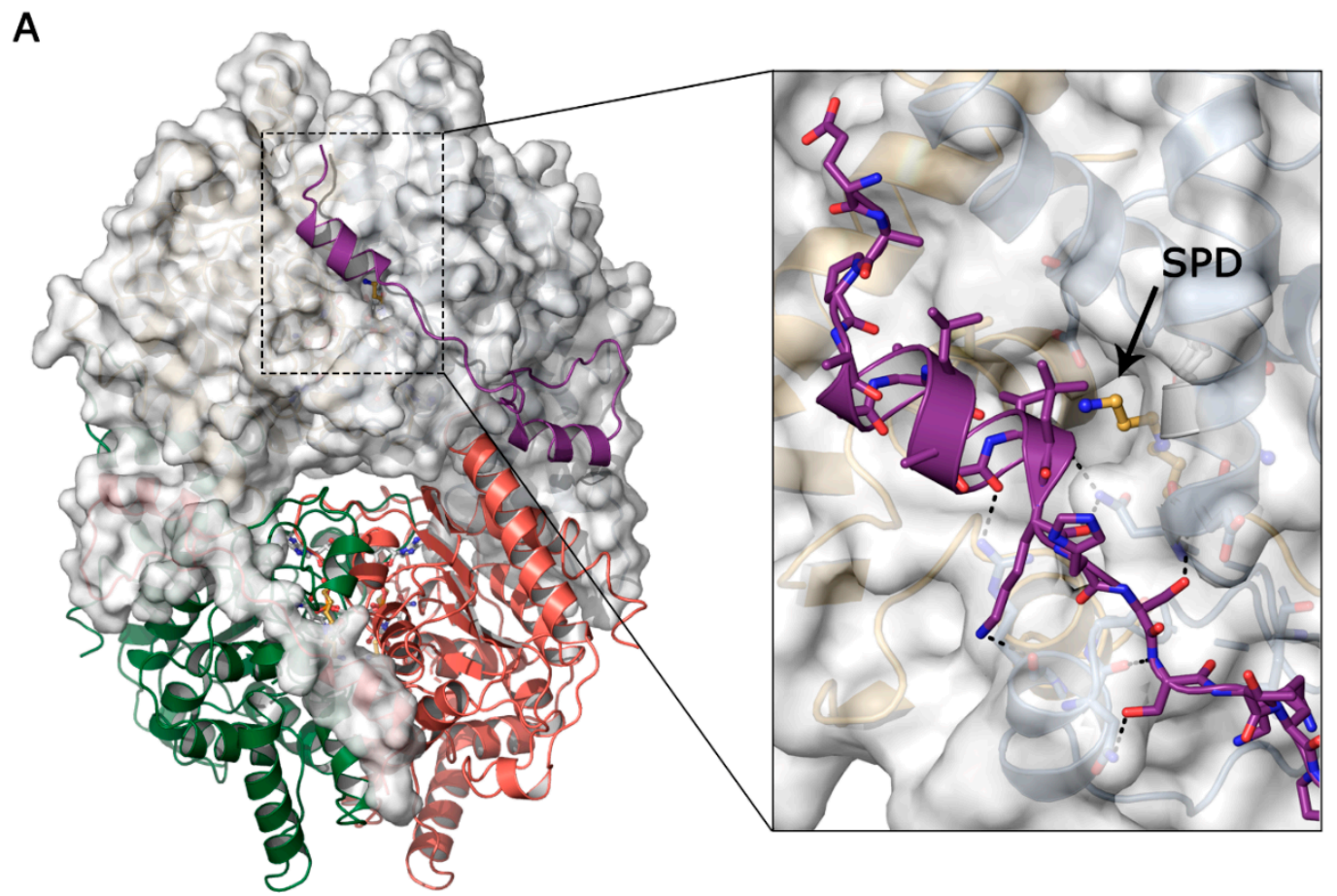

B

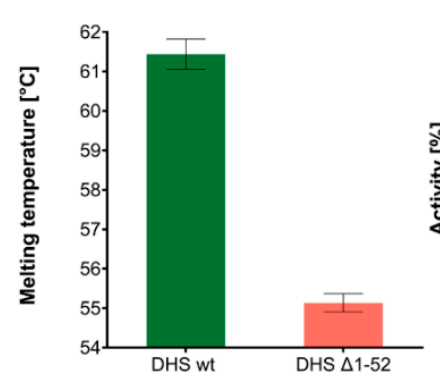

C

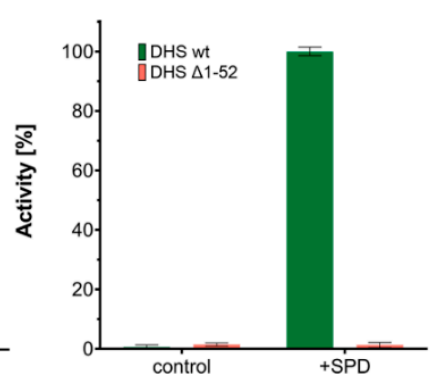

D

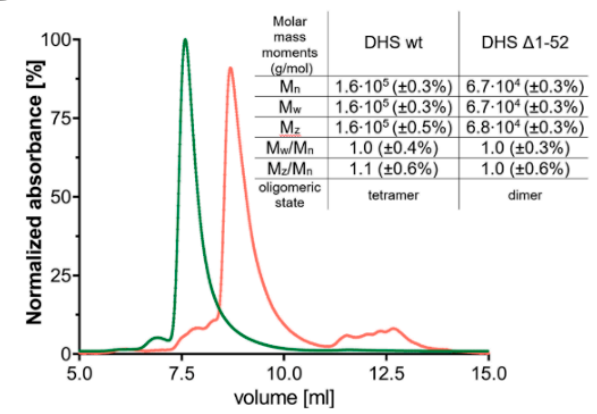

Figure 3. The role of the ball-and-chain motif. (A) The structure of DHS-NAD-SPD is shown with one dimer as a cartoon and one in surface representation. The ball-and-chain motif observed in subunit A is shown in purple. This region folds on the symmetry-related subunit over the entry to the active site. The enlargement shows the hydrogen bond network (black dashed lines) of the N-terminal fragment with the globular part of the enzyme. The opening of a tunnel, leading to the active site and a spermidine residue within, is indicated by an arrow. (B) The decrease of stability of the truncation mutant expressed as a drop in the measured Tm. (C) The relative activity of wild-type DHS and its truncation mutant. (D) The SEC-MALS elution profiles of wild-type and truncated DHS. The table summarises the numerical results of the MALS measurement. In all plots, green refers to the full-length DHS and red to the truncated DHS.

\subsection{The Ball-and-Chain Motif Is Crucial for DHS Activity, Stability and Oligomerisation}

The high resolution of the presented structural data enables the tracing of an N-terminal ball-and-chain motif, which is comprised of a short helix connected to the core of DHS by a long flexible linker. The ball-and-chain motif encompasses residues 1-52 and contributes significantly to the protein stability by winding around a symmetry-related monomer (Figure 3A).

Based on the comparative analysis of the herein described structures, we noticed an increased flexibility of this motif, as indicated by higher-than-average ADPs and a lack of interpretable electron density in the subunit B (Figure S1B). The absence of the electron density for residues 8-27 in one of the chains can be either a mere crystallisation artefact or it can indicate that it is only partially ordered. 
In the DHS-NAD-SPD complex, the $A: B^{\prime}$ interface is $3092 \AA^{2}$ and has a $\Delta G_{i}$ of $-43.2 \mathrm{kcal} / \mathrm{mol}$, of which as much as $1519 \AA^{2}$ and $-19.8 \mathrm{kcal} / \mathrm{mol}$ can be attributed to the aforementioned ball-and-chain motif [48]. In our structures, this ball-and-chain motif can be observed only in one chain in the asymmetric unit, and only for structures of complexes with SPD, and both SPD and NAD. To investigate the significance of this motif, we performed comparative studies between full length and truncated $(\Delta 1-52)$ versions of DHS. The Thermal Shift Assay shows that a lack of this N-terminal part results in a significant decrease in protein stability from $61.5 \pm 0.4$ to $55.1 \pm 0.4{ }^{\circ} \mathrm{C}$ (Figure 3B).

In the single turnover fluorescence assay performed for DHS $\Delta 1-52$, we observed an utter loss of spermidine dehydrogenation capacity, suggesting the importance of this motif for DHS functionality (Figure 3C). The absolute molecular weight measurements using MALS of both versions of the DHS protein show that without the ball-and-chain motif, the protein is not able to adopt a physiologically-active oligomeric state (Figure 3D). The elution time of DHS $\Delta 1-52$ indicates that the protein migrates in the form weighing approximately $68 \mathrm{kDa}$, which corresponds to the two monomers of the truncated version of the protein.

\section{Discussion}

Much attention is currently paid to the molecular mechanism of the selective control of protein translation by the hypusinated eIF5A. The DHS-catalysed reaction is a rate-limiting step in the hypusination pathway. Hence, a detailed knowledge of the reaction mechanism will help to understand the basics of this unique post-translational modification. Furthermore, since the hypusinated eIF5A is indispensable for tumour growth, as well as being closely related to the aggressiveness of cancers, the discovery of novel specific inhibitors of hypusination is highly awaited. Thus, the availability of high-resolution crystal structures in complex with natural ligands is essential to perform future structure-guided drug discovery attempts.

Low-resolution crystal structures of DHS have already been solved previously (PDB ID: 1RLZ, $1 R O Z, 1 R Q D, 1 D H S)$, yet our studies show not only more precise information due to significantly higher resolution, but also the enzyme in its apo form, as well as a detailed mode of binding of different polyamines. Previous findings suggested major conformational changes upon SPD and NAD binding; however, our structural data did not confirm this hypothesis (Figure S1B). Furthermore, it seems that substrate and co-factor binding influences only the active site of the protein and does not transmit any major conformational changes globally. Also, the study by Lee and Park proposes that SPD binding occurs following conformational changes induced by NAD binding [47]. Nonetheless, the DHS-SPD structure presented in our study challenges this suggestion, as SPD can bind DHS even in the absence of NAD. Structural studies on GC7-bound DHS underlined the importance of the His288 residue being a proton acceptor/donor during the DHS-catalysed reaction [36]. Our findings confirmed the proposed role of this invariant histidine. The comparison of binary DHS-SPD and ternary DHS-NAD-SPD complexes revealed an SPD conformational change, which is reflected in the change of distances between SPD C5, His288 and catalytical lysine 329.

To structurally describe substrate specificity, we determined the structures of DHS in complex with SPD and SPM. Both polyamines bind to DHS in the absence of NAD. Despite the almost identical mode of binding, only SPD serves as an appropriate DHS substrate. SPM activates DHS to a lesser extent than SPD, and its significantly higher flexibility probably excludes it as a substrate. Furthermore, our study refines a previously-proposed spermidine binding model. Briefly, we could observe the additional interaction of the SPD moiety with Asn292 and an additional stabilising hydrophobic interaction with NAD in the DHS-NAD-SPD complex.

Following the earlier reports on the role of PUT as a 4-aminobutyl acceptor, which essentially can substitute the eIF5A precursor, we successfully attempted to solve the DHS-PUT binary complex [53]. We observed that, to some extent, the PUT molecule accommodates an SPD binding site; however, as it is shorter than SPD, it is placed too distant to be involved catalytically with K329 (Figure 2E). 
This finding is also in agreement with the results of an activity assay that shows that, in contrast to SPD and SPM, PUT cannot serve as a reductive agent for NADH formation (Figure 2F).

As described in the introduction, the DHS-catalysed reaction can be divided into four steps, and previous studies demonstrated that the first two steps of the reaction, namely NAD-dependent spermidine oxidation and dehydrospermidine cleavage, take place even in the absence of the eIF5A [27]. It was speculated that possible reaction products could be 1,3-diaminopropane and $\Delta^{1}$-pyrroline, which follows the intermediate formation at the Lys329 residue. This reaction is believed to be insignificant in the physiological context [25]. Here we show that DAP inhibits the DHS-catalysed reaction; however, the inhibitory effect is significantly lower than that described for GC7 (Figure S2F). Furthermore, our studies exemplify the role of NAD in the stabilisation of a transition state during the nucleophilic attack of SPD C 5 on K239 N $\varepsilon$. We could observe that the distance from the $\varepsilon$-amine group of the catalytic K329 to SPD's C5 in the binary complex (DHS-SPD) is significantly shortened to in the ternary (DHS-SPD-NAD) one in the presence of NAD.

In the first study reporting the human DHS-NAD crystal structure, Liao and colleagues have attempted to use 1,7-aminoheptane, a SPD analogue, to uncover the structural determinants of substrate binding [37]. Nonetheless, they could not unambiguously locate this compound within the electron density in the active site. However, they reported a patch of continuous electron density found at the bottom of the inner pocket, which could not be explained by the 9-atom 1,7-aminoheptane moiety. The authors hypothesized that this density could be attributed to either a 4-aminobutyl moiety in a cyclised form $\left(\Delta^{-1}\right.$-pyrroline 5 -carboxylate) or as its straight-chain derivative. In the structure of DHS in complex with NAD, we also carefully inspected the calculated electron density. As a result, we have found an unexplained electron density localised at the DHS dimer-dimer interface. The above mentioned $\Delta^{-}{ }^{1}$-pyrroline 5 -carboxylate fits well in this density, but does not entirely satisfy it. As we could not confirm its nature, therefore, we can only speculate that it may be a yet unidentified product of the DHS-catalysed reaction.

DHS forms an active homotetrameric assembly. Earlier studies identified a so-called ball-and-chain motif governing the entrance to an active site that hinders the substrate binding. Hence, it is believed that this N-terminal part of the protein undergoes a major conformational change upon both SPD and eIF5A binding. Furthermore, it has been shown that the deletion of this N-terminal part [54] inactivates DHS. Here, using the fluorescence activity assay and light scattering approach, we demonstrate that this N-terminal part of the protein (1-52) is indispensable not only for DHS activity but also for functional tetramer formation. Our results are in agreement with a previous report showing that the truncation of $48 \mathrm{~N}$-terminal residues in yeast DHS inactivates the protein [54]. This inactivation may be not only associated with the role of the ball-and-chain motif in governing the active site entry, but also to the loss of the functional tetrameric conformation. The DHS active site is completely formed by two chains, so one may anticipate that the tetramer dissociation into dimers will not compromise the active site. On the other hand, dimer formation would also increase the solvent accessibility and hence it could lead to the destabilisation of the active site architecture. In consequence, with such an effect, the co-factor NAD may either adopt altered conformation or its binding could be compromised. Although this hypothesis is supported by the observed decrease in protein stability (Figure 3B), more extensive research, such as advanced quantum mechanics simulations studies, would be required.

The DHS structures reported herein lay the ground for the better understanding of substrate recognition, which may in turn be utilised in the design of novel pharmaceutics. However, cancer is not the only disease in which DHS plays a role. Recently, two mutations in the dhps gene were associated with the newly recognised DHS deficiency syndrome, manifested by a variety of clinical symptoms [31]. The first of the mutations leads to deletion of two amino acids, 305Y and 306I, located in one of $\beta$-strands forming the NAD binding Rossman fold. This deletion is likely to structurally destabilise and/or diminish the co-factor binding. The second mutation is an N173S substitution. Asparagine 173 is located at the entry of a tunnel connecting the SPD binding site with the protein exterior. Alterations 
in this region are likely to affect polyamine substrate/product exchange. More studies are needed to fully understand the impact of these mutations on the enzyme's functionality.

\section{Conclusions}

In conclusion, our study, containing six novel high-resolution structures, provides a comprehensive framework for the future development of DHS-specific inhibitors. Notably, our findings close the remaining gap in the knowledge of substrate binding and recognition by DHS. Undeniably, future structural studies on eIF5A binding will shed more light on the DHS conformational changes during deoxyhypusine synthesis.

Supplementary Materials: The following are available online at http://www.mdpi.com/2218-273X/10/4/522/ s1, Video S1: Overall structure of DHS. Figure S1: Structural features of DHS. Figure S2: DHS substrate binding characteristics.

Author Contributions: P.G. designed and initiated the research; E.W., P.W. and P.G. expressed and purified the protein; collected X-ray diffraction data and solved and refined the structure; performed all experiments and analysed the data; wrote the manuscript. All authors have read and agreed to the published version of the manuscript.

Funding: The research has been supported by National Science Centre (NCN, Poland) research grant no. UMO-2019/33/B/NZ1/01839 to P.G. This project has received funding from the European Union's Horizon 2020 research and innovation programme under grant agreement No 730872. We acknowledge the МСB Structural Biology Core Facility (supported by the TEAM TECH CORE FACILITY/2017-4/6 grant from the Foundation for Polish Science) for valuable support.

Acknowledgments: X-ray data were collected at the BESSY II 14.1 beamline at Helmholtz-Zentrum Berlin für Materialien und Energie. We thank HZB for the allocation of synchrotron radiation beamtime. We would particularly like to acknowledge the support of Christian Feiler, Martin Gerlach and Manfred S. Weiss. We would like to thank Piotr Małecki for help with light scattering measurements, Klaudia Woś for invaluable support in crystallization trials, Marcin Kamiński for stimulating discussions and inspiration and Ban Judek for proofreading and valuable comments.

Conflicts of Interest: The authors declare no conflict of interest.

\section{References}

1. Cooper, H.L.; Park, M.H.; Folk, J.E. Posttranslational formation of hypusine in a single major protein occurs generally in growing cells and is associated with activation of lymphocyte growth. Cell 1982, 29, 791-797. [CrossRef]

2. Park, M.H. The Essential Role of Hypusine in Eukaryotic Translation Initiation. J. Biol. Chem. 1989, 264, 18531-18535. [PubMed]

3. Park, M.H.; Wolff, E.C.; Smit-McBride, Z.; Hershey, J.W.B.; Folk, J.E. Comparison of the activities of variant forms of eIF-4D: The requirement for hypusine or deoxyhypusine. J. Biol. Chem. 1991, 266, 7988-7994.

4. Wolff, E.C.; Kang, K.R.; Kim, Y.S.; Park, M.H. Posttranslational synthesis of hypusine: Evolutionary progression and specificity of the hypusine modification. Amino Acids 2007, 71, 233-236.

5. Park, M.H.; Wolff, E.C. Hypusine, a polyamine-derived amino acid critical for eukaryotic translation. J. Biol. Chem. 2018, 293, 18710-18718. [CrossRef]

6. Saini, P.; Eyler, D.E.; Green, R.; Dever, T.E. Hypusine-containing Protein eIF5A Promotes Translation Elongation. Nature 2011, 459, 118-121. [CrossRef]

7. Pelechano, V.; Alepuz, P. EIF5A facilitates translation termination globally and promotes the elongation of many non polyproline-specific tripeptide sequences. Nucleic Acids Res. 2017, 45, 7326-7338. [CrossRef]

8. Lassak, J.; Wilson, D.N.; Jung, K. Stall no more at polyproline stretches with the translation elongation factors EF-P and IF-5A. Mol. Microbiol. 2016, 99, 219-235. [CrossRef]

9. Mandal, A.; Mandal, S.; Park, M.H. Genome-wide analyses and functional classification of proline repeat-rich proteins: Potential role of eIF5A in eukaryotic evolution. PLoS ONE 2014, 9, e111800. [CrossRef]

10. Schnier, J.; Schwelberger, H.G.; Smit-McBride, Z.; Kang, H.A.; Hershey, J.W. Translation initiation factor 5A and its hypusine modification are essential for cell viability in the yeast Saccharomyces cerevisiae. Mol. Cell. Biol. 1991, 11, 3105-3114. [CrossRef] 
11. Pällmann, N.; Braig, M.; Sievert, H.; Preukschas, M.; Hermans-Borgmeyer, I.; Schweizer, M.; Nagel, C.H.; Neumann, M.; Wild, P.; Haralambieva, E.; et al. Biological relevance and therapeutic potential of the hypusine modification system. J. Biol. Chem. 2015, 290, 18343-18360. [CrossRef] [PubMed]

12. Park, M.H.; Wolff, E.C.; Folk, J.E. Is hypusine essential for eukaryotic cell proliferation? Trends Biochem. Sci. 1993, 18, 475-479. [CrossRef]

13. Oliverio, S.; Corazzari, M.; Sestito, C.; Piredda, L.; Ippolito, G.; Piacentini, M. The spermidine analogue GC7 (N1-guanyl-1,7-diamineoheptane) induces autophagy through a mechanism not involving the hypusination of eIF5A. Amino Acids 2014, 46, 2767-2776. [CrossRef] [PubMed]

14. Kaiser, A. Translational control of eIF5A in various diseases. Amino Acids 2012, 42, 679-684. [CrossRef]

15. Hoque, M.; Hanauske-Abel, H.M.; Palumbo, P.; Saxena, D.; D'Alliessi Gandolfi, D.; Park, M.H.; Pe'ery, T.; Mathews, M.B. Inhibition of HIV-1 gene expression by Ciclopirox and Deferiprone, drugs that prevent hypusination of eukaryotic initiation factor 5A. Retrovirology 2009, 6, 90. [CrossRef]

16. Nakanishi, S.; Cleveland, J.L. Targeting the polyamine-hypusine circuit for the prevention and treatment of cancer. Amino Acids 2016, 48, 2353-2362. [CrossRef]

17. Maier, B.; Nadler, J.L.; Raghavendra, G.; Maier, B.; Ogihara, T.; Trace, A.P.; Tersey, S.A.; Robbins, R.D.; Chakrabarti, S.K.; Dondero, R.S.; et al. The unique hypusine modification of eIF5A promotes islet $\beta$ cell inflammation and dysfunction in mice. J. Clin. Investig. 2010, 12, 2156-2170. [CrossRef]

18. Caraglia, M.; Park, M.H.; Wolff, E.C.; Marra, M.; Abbruzzese, A. EIF5A isoforms and cancer: Two brothers for two functions? Amino Acids 2013, 44, 103-109. [CrossRef]

19. Tong, Y.; Park, I.; Hong, B.-S.; Nedyalkova, L.; Tempel, W.; Park, H.-W. Crystal structure of human eIF5A1: Insight into functional similarity of human eIF5A1 and eIF5A2. Proteins 2009, 75, 1040-1045. [CrossRef]

20. Clement, P.M.J.; Henderson, C.A.; Jenkins, Z.A.; Smit-McBride, Z.; Wolff, E.C.; Hershey, J.W.B.; Park, M.H.; Johansson, H.E. Identification and characterization of eukaryotic initiation factor 5A-2. Eur. J. Biochem. 2003, 270, 4254-4263. [CrossRef]

21. Scuoppo, C.; Miething, C.; Lindqvist, L.; Reyes, J.; Ruse, C.; Appelmann, I.; Yoon, S.; Krasnitz, A.; Teruya-Feldstein, J.; Pappin, D.; et al. A tumour suppressor network relying on the polyamine-hypusine axis. Nature 2012, 487, 244-248. [CrossRef] [PubMed]

22. Meng, Q.B.; Kang, W.M.; Yu, J.C.; Liu, Y.Q.; Ma, Z.Q.; Zhou, L.; Cui, Q.-C.; Zhou, W.-X. Overexpression of eukaryotic translation initiation factor 5A2 (EIF5A2) correlates with cell aggressiveness and poor survival in gastric cancer. PLoS ONE 2015, 10, e0119229. [CrossRef] [PubMed]

23. Lu, J.; Zhao, H.; Chen, Y.; Wei, J.; Chen, Z.; Feng, Z.; Huang, Y.; Chen, W.; Luo, J.; Fang, Y. Eukaryotic translation initiation factor $5 \mathrm{~A} 2$ is highly expressed in prostate cancer and predicts poor prognosis. Exp. Ther. Med. 2019, 17, 3741-3747. [CrossRef] [PubMed]

24. Mantuano, E.; Trettel, F.; Olsen, A.S.; Lennon, G.; Frontali, M.; Jodice, C. Localization and genomic structure of human deoxyhypusine synthase gene on chromosome 19p13.2-distal 19p13.1. Gene 1998, 215, 153-157. [CrossRef]

25. Wolff, E.C.; Wolff, J.; Park, M.H. Deoxyhypusine synthase generates and uses bound NADH in a transient hydride transfer mechanism. J. Biol. Chem. 2000, 275, 9170-9177. [CrossRef] [PubMed]

26. Wolff, E.C.; Park, M.H.; Folk, J.E. Cleavage of spermidine as the first step in deoxyhypusine synthesis. The role of NAD+. J. Biol. Chem. 1990, 265, 4793-4799.

27. Wolff, E.C.; Folk, J.E.; Park, M.H. Enzyme-substrate intermediate formation at lysine 329 of human deoxyhypusine synthase. J. Biol. Chem. 1997, 272, 15865-15871. [CrossRef]

28. Joe, Y.A.; Wolff, E.C.; Lee, Y.B.; Park, M.H. Enzyme-Substrate Intermediate at a Specific Lysine Residue Is Required for Deoxyhypusine Synthesis. J. Biol. Chem. 2002, 272, 32679-32685. [CrossRef]

29. Myung, H.P.; Wolff, E.C.; Young, B.L.; Folk, J.E. Antiproliferative effects of inhibitors of deoxyhypusine synthase. Inhibition of growth of Chinese hamster ovary cells by guanyl diamines. J. Biol. Chem. 1994, 269, 27827-27832.

30. Templin, A.T.; Maier, B.; Nishiki, Y.; Tersey, S.A.; Mirmira, R.G. Deoxyhypusine synthase haploinsufficiency attenuates acute cytokine signaling. Cell Cycle 2011, 10, 1043-1049. [CrossRef]

31. Ganapathi, M.; Padgett, L.R.; Yamada, K.; Devinsky, O.; Willaert, R.; Person, R.; Au, P.-Y.B.; Tagoe, J.; McDonald, M.; Karlowicz, D.; et al. Recessive Rare Variants in Deoxyhypusine Synthase, an Enzyme Involved in the Synthesis of Hypusine, Are Associated with a Neurodevelopmental Disorder. Am. J. Hum. Genet. 2019, 104, 287-298. [CrossRef] [PubMed] 
32. Lee, Y.; Kim, H.K.; Park, H.E.; Park, M.H.; Joe, Y.A. Effect of N1-guanyl-1,7-diaminoheptane, an inhibitor of deoxyhypusine synthase, on endothelial cell growth, differentiation and apoptosis. Mol. Cell. Biochem. 2002, 237, 69-76. [CrossRef]

33. Lee, S.K.; Lee, J.; Lee, S.I.; Bae, W.J.; Lee, Y.M.; Park, J.S.; Lee, S.-K.; Park, S.-J.; Min, S.-K.; Kim, E.-C. N1-guanyl-1,7,-diamineoheptane, an inhibitor of deoxyhypusine synthase, suppresses differentiation and induces apoptosis via mitochondrial and AMPK pathways in immortalized and malignant human oral keratinocytes. J. Oral. Pathol. Med. 2009, 38, 792-800. [CrossRef] [PubMed]

34. Schultz, C.R.; Geerts, D.; Mooney, M.; El-Khawaja, R.; Koster, J.; Bachmann, A.S. Synergistic drug combination GC7/DFMO suppresses hypusine/spermidine-dependent eIF5A activation and induces apoptotic cell death in neuroblastoma. Biochem. J. 2018, 475, 531-545. [CrossRef] [PubMed]

35. Ning, Q.U.; Ignatenko, N.A.; Yamauchi, P.; Stringer, D.E.; Levenson, C.; Shannon, P.; Shannon, P.; Perrin, S.; Gerner, E.W. Inhibition of human ornithine decarboxylase activity by enantiomers of difluoromethylornithine. Biochem. J. 2003, 375, 465-470.

36. Umland, T.C.; Wolff, E.C.; Park, M.H.; Davies, D.R. A new crystal structure of deoxyhypusine synthase reveals the configuration of the active enzyme and of an enzyme-NAD·inhibitor ternary complex. J. Biol. Chem. 2004, 279, 28697-28705. [CrossRef] [PubMed]

37. Liao, D.-I.; Wolff, E.C.; Park, M.H.; Davies, D.R. Crystal structure of the NAD complex of human deoxyhypusine synthase: An enzyme with a ball-and-chain mechanism for blocking the active site. Structure 2004, 6, 23-35. [CrossRef]

38. Gorrec, F. Protein crystallization screens developed at the MRC Laboratory of Molecular Biology. Drug Discov. Today 2016, 21, 819-825. [CrossRef]

39. Mueller, U.; Darowski, N.; Fuchs, M.R.; Förster, R.; Hellmig, M.; Paithankar, K.S.; Pühringer, S.; Steffien, M.; Zocher, G.; Weiss, M.S. Facilities for macromolecular crystallography at the Helmholtz-Zentrum Berlin. J. Synchrotron. Radiat. 2012, 19, 442-449. [CrossRef]

40. Sparta, K.M.; Krug, M.; Heinemann, U.; Mueller, U.; Weiss, M.S. Xdsapp2.0. J. Appl. Crystallogr. 2016, 49, 1085-1092. [CrossRef]

41. McCoy, A.J.; Grosse-Kunstleve, R.W.; Adams, P.D.; Winn, M.D.; Storoni, L.C.; Read, R.J. Phaser crystallographic software. J. Appl. Crystallogr. 2007, 40, 658-674. [CrossRef] [PubMed]

42. Emsley, P.; Lohkamp, B.; Scott, W.G.; Cowtan, K. Features and development of Coot. Acta Crystallogr. Sect. D Biol. Crystallogr. 2010, 66, 486-501. [CrossRef] [PubMed]

43. Afonine, P.V.; Grosse-Kunstleve, R.W.; Echols, N.; Headd, J.J.; Moriarty, N.W.; Mustyakimov, M.; Terwilliger, T.C.; Urzhumtsev, A.; Zwart, P.H.; Adams, P.D. Towards automated crystallographic structure refinement with phenix.refine. Acta Crystallogr. Sect. D Biol. Crystallogr. 2012, 68, 352-367. [CrossRef] [PubMed]

44. Joosten, R.P.; Long, F.; Murshudov, G.N.; Perrakis, A. The PDB_REDO server for macromolecular structure model optimization. IUCrJ 2014, 1, 213-220. [CrossRef] [PubMed]

45. Afanador, G.A.; Tomchick, D.R.; Phillips, M.A. Trypanosomatid Deoxyhypusine Synthase Activity Is Dependent on Shared Active-Site Complementation between Pseudoenzyme Paralogs. Structure 2018, 26, 1499-1512. [CrossRef] [PubMed]

46. Reinhard, L.; Mayerhofer, H.; Geerlof, A.; Mueller-Dieckmann, J.; Weiss, M.S. Optimization of protein buffer cocktails using Thermofluor. Acta Crystallogr. Sect. F Struct. Biol. Cryst. Commun. 2013, 69, 209-214. [CrossRef] [PubMed]

47. Lee, C.H.; Park, M.H. Human deoxyhypusine synthase: Interrelationship between binding of NAD and substrates. Biochem. J. 2000, 352, 851-857. [CrossRef]

48. Krissinel, E.; Henrick, K. Inference of Macromolecular Assemblies from Crystalline State. J. Mol. Biol. 2007, 372, 774-797. [CrossRef]

49. Hoon, L.C.; Um, P.Y.; Hee, P.M. Structure-function studies of human deoxyhypusine synthase: Identification of amino acid residues critical for the binding of spermidine and NAD. Biochem. J. 2001, 355, 841-849.

50. Igarashi, K.; Kashiwagi, K. The functional role of polyamines in eukaryotic cells. Int. J. Biochem. Cell Biol. 2019, 107, 104-115. [CrossRef]

51. Laube, G.; Bernstein, H.G. Agmatine: Multifunctional arginine metabolite and magic bullet in clinical neuroscience? Biochem. J. 2017, 474, 2619-2640. [CrossRef] [PubMed] 
52. Šečkute, J.; McCloskey, D.E.; Thomas, H.J.; Secrist, J.A.; Pegg, A.E.; Ealick, S.E. Binding and inhibition of human spermidine synthase by decarboxylated S-adenosylhomocysteine. Protein Sci. 2011, 20, 1836-1844. [CrossRef] [PubMed]

53. Park, J.H.; Wolff, E.C.; Folk, J.E.; Park, M.H. Reversal of the deoxyhypusine synthesis reaction: Generation of spermidine or homospermidine from deoxyhypusine by deoxyhypusine synthase. J. Biol. Chem. 2003, 278, 32683-32691. [CrossRef] [PubMed]

54. Young, A.J.; Wolff, E.C.; Myung, H.P. Cloning and expression of human deoxyhypusine synthase cDNA. Structure- function studies with the recombinant enzyme and mutant proteins. J. Biol. Chem. 1995, $270,22386-22392$.

(C) 2020 by the authors. Licensee MDPI, Basel, Switzerland. This article is an open access article distributed under the terms and conditions of the Creative Commons Attribution (CC BY) license (http://creativecommons.org/licenses/by/4.0/). 